\title{
Детальная оценка новейших тектонических напряжений в районе пролива Великая Салма (Кандалакшский залив) по тектонофизическим данным
}

\author{
Бондарь И.В. ${ }^{1}$, Шварев С.В. ${ }^{1,2}$ \\ ${ }^{1}$ Институт физики Земли им. О.Ю. Шмидта РАН, Москва, bond@ifz.ru \\ ${ }^{2}$ Институт географии РАН, Москва, shvarev@ifz.ru
}

Аннотация. В 2019 году в ходе полевых работ были изучены острова Кузокоцкого архипелага и полуострова Киндо (побережье Кандалакшского залива Белого моря). Набран уникальный материал для тектонофизических исследований: замеры пространственной ориентировки зеркал скольжения, трещин, жил, отрывов и других геологических индикаторов стресс-деформаций. По результатам реконструкции напряженного состояния методом катакластического анализа Ребецкого Ю.Л. показано, что в большинстве точек наблюдения оси максимального сжатия имеют ориентировку северо-восток - юго-запад. В связи с этим сделан предположительный вывод, что пролив Великая Салма маркирует зону растяжения, которая развивается совместно с Кандалакшским заливом.

Ключевые слова: неотектоника, тектонофизика, тектонические напряжения, главные оси напряжений, зеркала скольжения, Кандалакшский залив, Белое море, пролив Великая Салма.

\section{Detailed assessment of the neotectonic stresses in the area of the Great Salma Strait (Kandalaksha Gulf) using tectonophysical data}

\author{
Bondar I.V. ${ }^{1}$, Shvarev S.V. ${ }^{1,2}$ \\ ${ }^{1}$ The Schmidt Institute of Physics of the Earth of the Russian Academy of Sciences \\ ${ }^{2}$ Institute of Geography, Russian Academy of Sciences
}

\begin{abstract}
In 2019, during the field work, the Islands of the Kuzokotsky archipelago and the Kindo Peninsula (the coast of the Kandalaksha Bay of the White Sea) were studied. A unique material for tectonophysical research has been collected: measurements of spatial orientation of slickenside, cracks, veins, breaks, and other geological indicators of stress deformations. Based on the results of reconstruction of the stress state by the method of cataclastic analysis of Rebetsky Yu. L.., it is shown that in most points of observation, the axes of maximum compression have a North-East - South-West orientation. In this regard, it is assumed that the Great Salma Strait marks the stretch zone that is developing together with the Kandalaksha Gulf.
\end{abstract}

Key words: neotectonics, tectonophysics, tectonic stresses, main stress axes, slickenside, Kandalaksha Gulf, White Sea, Great Salma Strait.

\section{Введение}

В 2019 году в ходе совместных полевых работ Института географии РАН, МГУ им. М.В. Ломоносова и Института физики Земли им. О.Ю. Шмидта РАН были изучены острова Кузокоцкого архипелага и полуостров Киндо. Набран уникальный материал для тектонофизических исследований. В данной работе показаны результаты первичной обработки набранных материалов и сделаны первые, предположительные выводы.

Район исследования расположен на границе республики Карелия и Мурманской области, на Карельском побережье Кандалакшского залива Белого моря. Детально изучен полуостров Киндо, на котором находится Беломорская биологическая станция им. Н.А. Перцова, а также острова Кузокоцкого архипелага (рис. 1).

\section{Методика исследования}

Реконструкция напряженно-деформированного состояния проводится по данным полевых замеров пространственной ориентировки трещиноватости, жил, отрывов, даек и зеркал скольжения. Для реконструкции используется метод катакластического анализа Ребецкого Ю.Л. (Ребецкий Ю.Л. и др., 2017). 

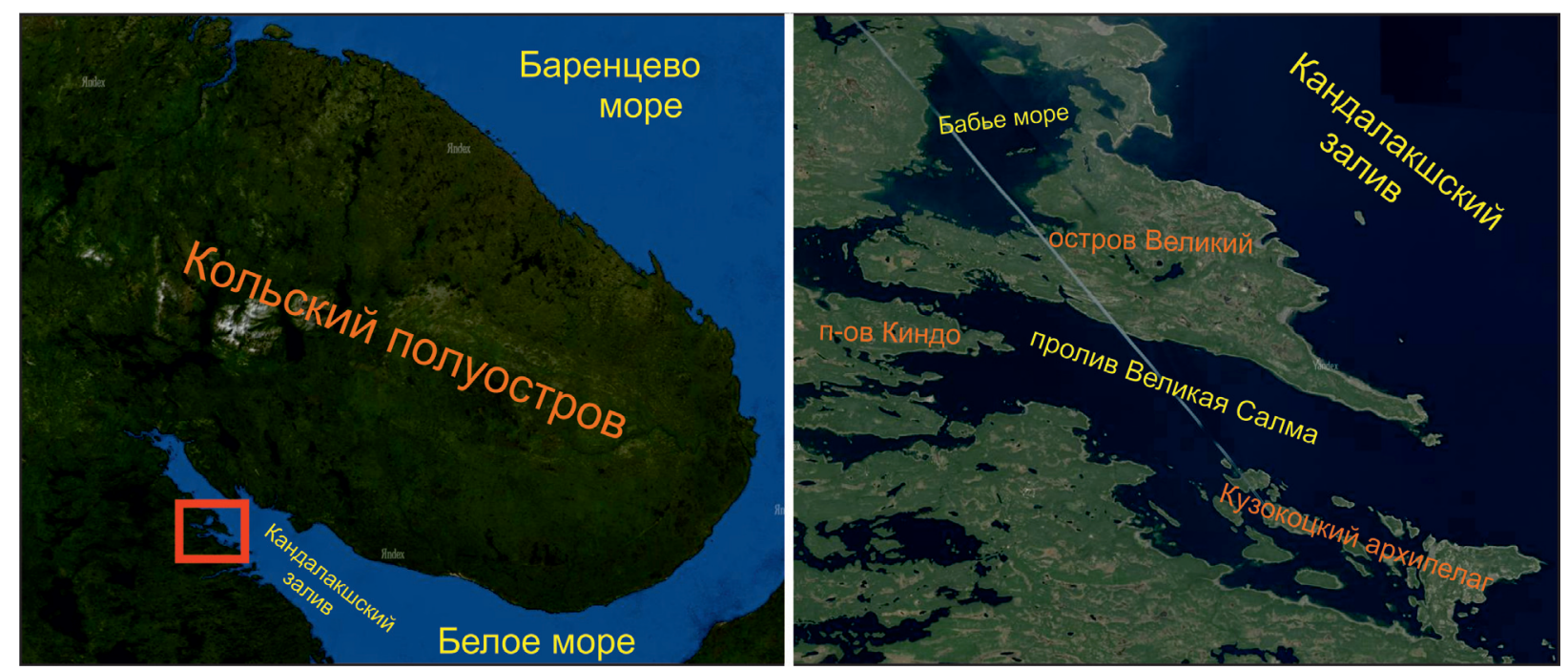

Рис. 1. Район исследования. Fig. 1. Study area.

Реконструкция производится с помощью программы STRESSgeol, разработанной автором данного метода. Метод катакластического анализа позволяет определить количественные характеристики реконструируемых локальных стресс-состояний: положение осей главных напряжений и коэффициент Лоде - Надаи.

\section{Результаты}

В результате обработки замеренных зеркал скольжения получено 11 локальных стрессиндикаторов. В западной части исследуемого района, на южном побережье Ругозерской губы фиксируется северо-восточное и северо-северо-восточное положение оси максимального сжатия. Положение оси практически горизонтально. Ось максимального растяжения довольно круто падает на юго-восток (рис. 2).

На северном побережье губы Кислой ось максимального круто падает на северо-восток, ось максимального растяжения круто падает на юго-запад, а промежуточная ось полого погружается на северо-запад.

На южном побережье губы Кислой в небольшом архейском массиве габбро-норитов ось максимального сжатия полого погружается на северо-запад, а ось максимального растяжения - на югозапад.

В восточной части изучаемого района на острове Кокоиха реконструировано два локальных стресс-состояния. И в двух точках положение осей практически совпадает: ось максимального сжатия полого погружается на юго-запад, ось максимального растяжения очень круто падает на северозапад.

На острове Медвежий положение оси максимального сжатия тоже совпадает с положением оси на острове Кокоиха - пологое погружение на юго-запад. Ось максимального растяжение также круто падает, но уже на восток.

На острове Покормежный зафиксировано такое положение осей максимального сжатия, которое больше не было нигде получено в данном районе - ось максимального сжатия полого погружается на восток, а ось максимального растяжения круто падает на север.

На безымянном острове (предлагаю дать ему имя), расположенном в губе Заволочье, по результатам расчет ось максимального сжатия простирается с юго-запада на северо-восток, а ось максимального растяжения - на юго-восток. Обе оси погружаются полого.

На южном побережье губы Поволочье ось максимального сжатия полого погружается на северо-восток, ось максимального сжатия относительно круто падает на юго-восток.

На север от острова Великий на мысе Купчинницком получено локальное стресс-состояние, отвечающее растяжению - ось максимального сжатия практически вертикальна, а ось максимального растяжения и промежуточная ось - горизонтальны. 
Распределение осей всех рассчитанных стресс-состояний сведены на одну диаграмму и показаны на рисунке 3.

Интересно, что замеры зеркал скольжения на о. Медвежий, о. Покормежный и на безымянном небольшом островке проводились в той части островов, которые до недавнего времени находились под водой - на топографической карте 1950-х годов и геологической карте 1960-х годов их еще нет (собственно безымянный остров потому и безымянный, что был полностью под водами Белого моря во время топографической съемки).

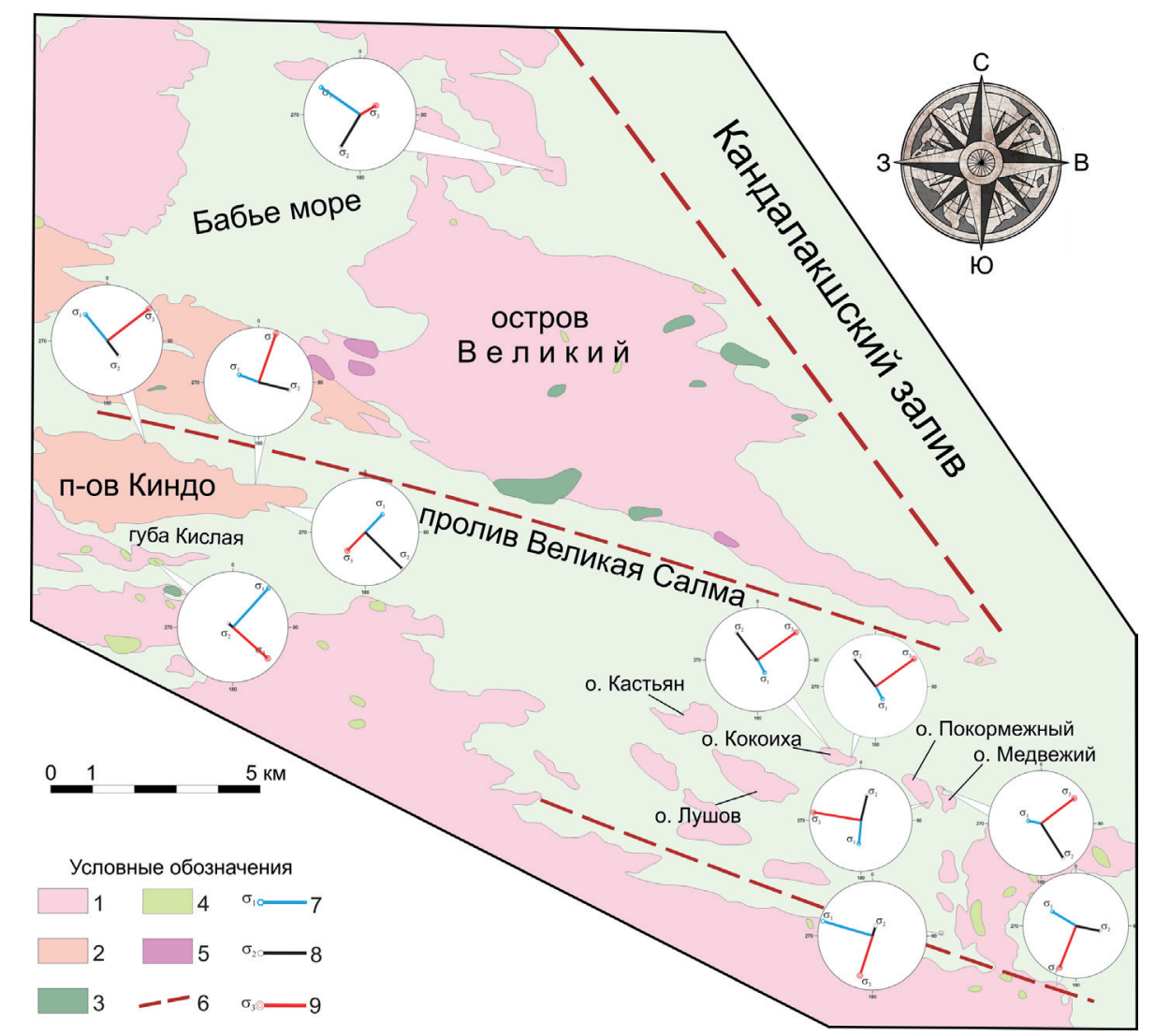

Рис. 2. Расположение рассчитанных локальных стресс-состояний. Каждое стресс-состояние показано в виде диаграммы с положением полюсов осей главных нормальных напряжений. Построения производились на верхнюю полусферу.

1 - Беломорская серия, нижняя (керетьская) толща. Биотитовые гнейсы и гранито-гнейсы, редко амфиболиты; 2 - Беломорская серия, средняя (хетоламбинская) толща. Амфиболиты, гранатовые, амфиболовые и биотитовые гнейсы, резко подчиненные кианито- и гранато-юиотитовые гнейсы; 3 - Ранние архейские интрузии, амфиболиты гранатовые и палевошпатовые; 4 - Поздние архейские интрузии, габбро-нориты, габбро, габбро-порфириты, микрогаббро, габро-амфиболиты, амфиболиты; 5 - Поздние архейские интрузии, плагиомикроклиновые и плагиоклазовые граниты и гнейсо-граниты; 6 - предполагаемые разломы; 7 - ось максимального растяжения; 8 - промежуточная ось; 9 - ось максимального сжатия.

Fig. 2. Location of the calculated local stress states. Each stress state is shown as a diagram with the location of poles of major normal pressure axes. The construction was made on the upper hemisphere.

1 - White Sea series, bottom (Keretskaya) sequence. Biotite gneisses and garnet gneisses, rarely amphibolites; 2 - White Sea series, middle (Khetolambinskaya) sequence. Amphibolites, garnet, amphibolite, and biotite gneisses, sharply subordinated kyanite and garnet-biotite gneisses; 3 - Early Archean intrusions, garnet and feldspar amphibolites; 4 - Late Archean intrusions, gabbro-norites, gabbro, gabbro-porphyrites, microgabbro, gabbroamphibolites, amphibolites; 5 - Late Archean intrusions, plagio-microcline and plagioclase granites and gneissgranites; 6 - approximate faults; 7 - maximum extension axis; 8 - transition axis; 9 - maximum compression axis. 

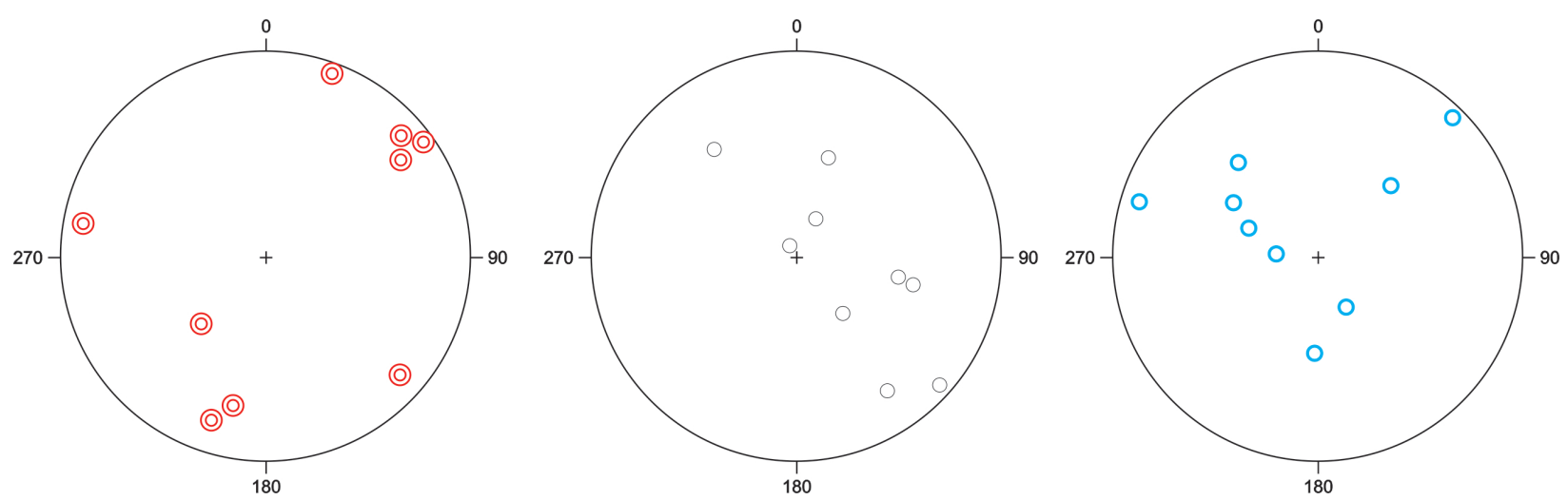

Рис. 3. Распределение полюсов осей всех рассчитанных локальных стресс-состояний. На левой диаграмме полюса осей максимального сжатия, на средней - полюса промежуточных осей, на левой - полюса осей максимального растяжения.

Fig. 3. Distribution of axes poles of all the calculated local stress states. The left diagram shows poles of maximum compression axes, the middle diagram presents poles of intermediate axes, the left one - poles of maximum extension axes.

\section{Обсуждение}

Влияние на Балтийский щит Северо-Атлантической зоны спрединга, а также современные вертикальные тектонические движения щита, одной из составляющих которых является гляциоизостатический эффект определяют современное распределение напряжений в земной коре (Балуев и др., 2012).

Однако формирование современного бассейна Белого моря имело структурно-тектоническую предопределенность. Тектоническая впадина современного Кандалакшского залива наследует или возрождает рифейский грабен, о чем свидетельствуют активные опускания авлакогена в новейшее время, сопровождаемые возрождением большинства разломов и проявлением вдоль них многочисленных очагов землетрясений (Балуев и др., 2012).

Согласно существующим взглядам, Кандалакшская сейсмогенная зона маркирует крупную зону растяжения в земной коре (Юдахин Ф.Н. и др., 2003).

Растяжение и, следовательно, распределение напряжений в Кандалакшском заливе объясняется противоположной направленностью вращения Кольского и Карельского массивов. На этот процесс накладываются гляциоизостатические деформации (Евзеров В.Я. и др., 2014).

В данной работе все полученные локальный стресс-состояния находятся не на берегу Кандалакшского залива, а в пределах пролива Великая Салма, который переходит в Ругозерскую губу и глубоко вдается в Карельский массив (длина залива 36 км). Вероятно, что и пролив участвует в общем растяжении и развивается по той же модели.

На южном борту пролива практически везде фиксируется северо-восточное сжатие и северо-западное растяжение (как раз по простиранию пролива), особенно четко оно проявлено на внешних островах Кузокоцкого архипелага - Кокоиха, Покормежный, Медвежий и полуострове Киндо (рис. 3). Скорее всего это связано с тем, что пролив Великая Салма маркирует зону растяжения, на бортах которой фиксируются области сжатия и сдвиги. Вообще, как отмечено в работе (Евзеров В.Я. и др., 2014), в Беломорской котловине сдвиги доминируют среди неотектонических разрывных нарушений. Сдвиговые смещения происходят по древним трещинам, обновленным на неотектоническом этапе.

Однако в работе (Старовойтов А. В. и др., 2018) в ходе детальных сейсмоакустических исследований получены результаты, на первый взгляд противоречащие сделанным выше выводам. По данным морфологического и структурного анализа ими выявлены основные разрывные нарушения преимущественно северо-западного и северо-восточного простирания, которые затрагивают архейские гнейсы, а на некоторых участках и позднеплейстоценовые, возможно, голоценовые осад- 


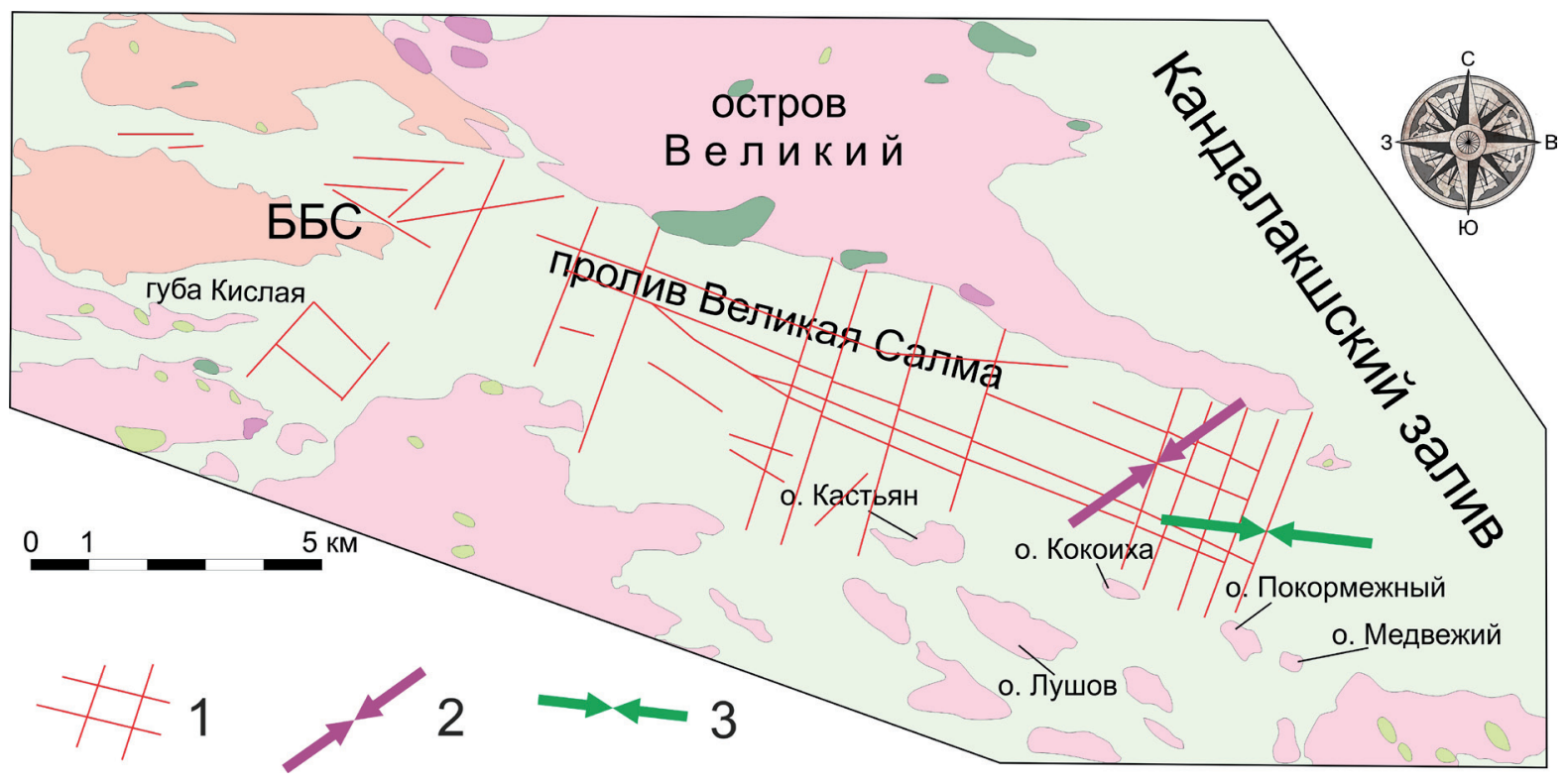

Рис. 4. Соотношение разломов, выделенных по геофизическим данным, и осей максимального сжатия.

1 - разломы, выделенные по сейсмоакустическим данным (Старовойтов А.В. и др., 2018); 2 - направление осей максимального сжатия по данным авторов статьи; 3 - направление осей максимального сжатия по данным (Баранская А.В. и др., 2015).

Fig. 4. Correlation of faults identified after the geophysical data and maximum compression axes.

1 - faults identified after the seismoacoustic data (Starovoytov A.V. et al., 2018); 2 - direction of maximum compression axes after the data of the authors of the paper; 3 - direction of maximum compression axes after the data (Baranskaya A.V. et al., 2015).

ки. Все выделенные разрывные нарушения имеют вертикальную амплитуду смещения, то есть являются сбросами или взбросами.

Но при такой ориентировке оси максимального сжатия (северо-восточная) и оси максимального растяжения (юго-восток) данные разрывные нарушения должны быть сдвигами, возможно с небольшой вертикальной компонентой (рис. 4).

Также в статье (Баранская А.В. и др., 2015) для данного района определено направление максимального главного нормального напряжения, которое имеет субширотную ориентировку. При такой ориентировке осей максимального сжатия разрывные нарушения, полученные в работе Старовойтова (Старовойтов А. В. и др., 2018), действительно будут иметь взбросовую компоненту (рис. 4).

Особого интереса заслуживает реконструированное локальное стресс-состояние на мысе Купчинницкий, так как там зафиксировано растяжение, тогда как в остальных точках наблюдения сжатие или сдвиг. Но для каких-либо выводов пока еще слишком мало информации.

\section{Выводы}

1. В большинстве точек наблюдения оси максимального сжатия имеют ориентировку северовосток - юго-запад.

2. Возможно, пролив Великая Салма маркирует зону растяжения, которая развивается совместно с Кандалакшским заливом

3. Имеющиеся противоречия результатов с работами других исследователей требуют дальнейшего изучения этого интересного региона.

\section{Благодарность}

Автор благодарит сотрудников Географического факультета МГУ им. М.В. Ломоносова Ф.А. Романенко, Н.Н. Лугового и Института географии РАН - Н.Е. Зарецкую за помощь в осуществлении полевых исследований. 


\section{Литература}

1. Балуев А.С., Журавлев В.А., Терехов Е.Н., Пржиялговский Е.С. Тектоника Белого моря и прилегающих территорий (Объяснительная записка к «Тектонической карте Белого моря и прилегающих территорий» масштаба 1:1500000) // Тр. ГИН РАН. Вып. 597. М.: ГЕОС. 2012. 104 с.

2. Баранская А. В., Романенко Ф. А. Дифференцированные вертикальные движения и блоковая тектоника побережий Кандалакшского залива Белого моря // Материалы IV Международной научно-практической конференции молодых ученых и специалистов памяти академика А.П. Карпинского, 16-20 февраля 2015 г., Санкт-Петербург. ФГУП ВСЕГЕИ. - ВСЕГЕИ г. Санкт-Петербург. 2015. С. 3-6.

3. Евзеров В.Я., Виноградов А.Н., Николаева С.Б. Геодинамика беломорской котловины в голоцене // Вестн. КНЦ РАН. 2014. № 2 (17). С. 51-58.

4. Ребецкий Ю.Л., Сим Л.А., Маринин А.В. От зеркал скольжения к тектоническим напряжениям. Методики и алгоритмы. М.: ГЕОС. 2017. 234 с.

5. Старовойтов А. В., Токарев М. Ю., Терехина Я. Е., Козупица Н. А. Строение осадочного чехла Кандалакшского залива Белого моря по данным сейсмоакустики // Вестник Московского университета. Серия 4: Геология. 2018. № 2. С. 81-92.

6. Юдахин Ф.Н., Щукин Ю.К., Макаров В.И. Глубинное строение и современные геодинамические процессы в литосфере Восточно-Европейской платформы. Екатеринбург: УрО РАН. 2003. 299 с. 